\title{
Chemical Control of Fertility in Male Dogs: A Review
}

\author{
Rakesh Kumar ${ }^{1}$, Nitin Soni ${ }^{2}$, Sandeep Kumar ${ }^{2}$ and Anand Kumar Pandey ${ }^{3}$ \\ ${ }^{1}$ Department of Animal Husbandry and Dairying, Haryana, India \\ ${ }^{2}$ Department of Veterinary Gynaecology \& Obstetrics, ${ }^{3}$ Department of Veterinary Clinical \\ Complex, Covs, Luvas, Hisar, India \\ *Corresponding author
}

\author{
A B S T R A C T
}

\section{Keywords}

Stray dogs,

Sterilization,

Contraception and

chemical methods.

Article Info

Accepted:

15 June 2018

Available Online:

10 July 2018
Stray dog population in Indian cities and towns has reached to about 30 million. Stray dog's overpopulation poses a major threat to human health through their role in disease transmission as more than 100 zoonotic diseases are transmitted from dog to humans. Surgical castration is being used in India for population control of stray dogs since 1994 but its impact on stray dog population is not noticeable. Chemical control of fertility seems an alternative viable approach due to many reasons and researchers have tried various chemical methods since last century to inhibit/suppress fertility in male dogs. Chemical sterilization/contraception methods so far employed includes chemosterilants, hormonal methods, phytoestrogens, immunological methods and other miscellaneous compounds and out of all these methods/chemicals some seems to be practical at grass root level however Michelson Prize of \$25 million is still waiting for its winner. We have made a brief summary of different types of chemical treatment methods that have either been tried in laboratories or field level in this review.

\section{Introduction}

The global population of dogs is estimated to be around 0.987 billion (Gompper, 2014). It has been estimated that approximately more than half of the global dog population are free roaming or stray dogs (Hassan and Fromsa, 2017). Stray dog can be defined as a dog not under direct control by a person or not prevented from roaming and further classified them into three types: a) free-roaming owned dog not under direct control or restriction at a particular time; b) free-roaming dog with no owner and c) feral dog: domestic dog that has reverted to the wild state and is no longer directly dependent upon humans (OIE, 2011). Stray dog population in Indian cities and towns has reached to about 30 million which amounts to 1 stray dog per 42 people in the country (Insightsonindia, 2016) and it is still increasing at an alarming rate.

Stray dog's overpopulation poses a major threat to human health through their role in disease transmission as more than 100 zoonotic diseases are transmitted from dog to humans. Stray dogs in India cause almost 96\% of rabies cases and rabies in India takes nearly 
30000 lives per year (Kumar, 2002). Stray dogs also pose other problems like dog attacks and biting, fear of dog bites and dog attacks in public, injury to livestock and pets including dogs, road accidents, attacking domestic animals, noise pollution, environmental pollution by open defecation, tearing open garbage (Butcher and Keuster, 2013), imbalance of forest ecosystem, damage of forests and crops and decrease in biodiversity (Ansari et al., 2017).

India has attempted to address its stray dog problem by mass killing e.g. killing of 50,000 street dogs annually by Municipal Corporation of Mumbai, India by electrocution in the past and through Animal Birth Control programme since 1994 (Ansari et al., 2017). But both strategies failed to make an impact as, the root problem of overpopulation remains unaltered because the surviving dogs breeding potential was unchecked. Animal Birth Control programme suffered because of lack of required coordination between the centre and the state governments, and between local authorities, implementation agencies, and other stake-holders within the states, inadequate grants (Supreme Court of India, 2016).

Stray dog population can be best managed by sterilizing male dogs as they have potential of impregnating large number of receptive females during the breeding season, so sterilizing number of males could conceivably decrease the number of pregnant female to the point of reversing population growth (Chaudhary et al., 2018). Surgical castration has been the only reliable and permanent method of sterilization of male animals and one English book on the art of hunting, dating back to 1575 has mentioned castration of male and female dogs (ACC\&D, 2013).Vasectomy which was first performed on a dog by Cooper in 1823 (Leavesley, 1980) and vasal occlusion are other surgical procedures which can be done for sterilization of male dogs. The limitation of surgical methods of sterilization includes requirement of skilled surgeons, anesthetic risks, bleeding, time consuming, costly, postoperative care and management to prevent infection (Jana and Samanta, 2007). Moreover, large-scale application of these methods for controlling the stray dogs menace is not practical.

Therefore, scientists have been interested in developing a wonder chemical/ drug for nonsurgical chemical sterilization for massscale application and which may be a better alternative to surgical methods. Chemical sterilization/contraception methods so far tried in laboratories and fields includes inorganic chemosterilants, hormonal methods, phytoestrogens, immunological methods and other miscellaneous compounds. An ideal chemical sterilizing agent for stray male dog population control would be one that is safe and has no deleterious side effects for the target and non-target species (including humans) in case of accidental exposure or self-injection; causes permanent loss of fertility; causes permanent loss of sexual behavior (WSPA, 2007), effective, easy to administer, single intervention workable at the trapping site, noninvasive/minimally invasive, simple, rapid and inexpensive with potential for adoption allowing animal welfare organizations, public health programs and governments (Ansari et al., 2017). A number of agents have been used for chemical sterilization of male dogs since last century but Michelson Prize of $\$ 25$ million to provide a low-cost, permanent, nonsurgical sterilant for male and female cats and dogs is still waiting for its winner (www.michelsonprizeandgrants.org).

Therefore, the objective of this paper is to review the literature of chemical sterilization/contraception agents used on male dogs and to assess the possibility of their applicability at grass root level. 


\section{Chemosterilants}

Chemosterilants have been tried as an alternative to surgical method of sterilization in male dogs. Chemosterilants eliminates hemorrhage, hernia, infection and other surgical complication and post-operative management usually. Various chemosterilants used in the past for population control of male dogs are briefly described in this review.

\section{Cadmium chloride}

Bekheet (2010) suggested that damage to Sertoli cell tight junctions induced by cadmium may be an underlying mechanism of its male-mediated reproductive toxicity.

Murty and Sastry (1978) administered $0.5 \mathrm{ml}$ of Cadmium chloride @ of $0.05 \mathrm{mg} / \mathrm{kg}$ dissolved in distilled water as a single intratesticular to adult male dogs and observed testes about size of pea and microscopically only a mass of fibrous tissue in testes and empty epididymis in treated animals after treatment. The authors concluded complete sterilization of male dogs with cadmium chloride was without any side effects.

\section{Calcium chloride}

Calcium chloride causes necrosis of the testicular tissue due to edema which leads to atrophy of testicular gland parenchyma and probably also by a high rate of free-radical generation in the testicular tissues and a low level of testosterone (Jana and Samanta, 2007). Jana and Samanta (2007) administered single bilateral intratesticular injection of calcium chloride solution containing 1\% lignocaine hydrochloride at the doses of 5,10 , 15 or $20 \mathrm{mg}$ per testis per $\mathrm{kg}$ body weight in dogs and reported high doses (15 or $20 \mathrm{mg}$ ) of $\mathrm{CaCl}_{2}$ treatment causes complete degeneration of germ cells and absence of a distinct boundary of seminiferous tubules with appearance of fibrous tissue and hyaline tissue. The signs of regeneration in germ cells and interstitial cells@20 mg were absent. Leoci et al., (2014) evaluated long-term efficacy of intratesticular injection of $20 \%$ $\mathrm{CaCl}_{2}$ in alcohol versus lidocaine for the relative ability to halt sperm production and authors concluded that alcohol was a superior solution for $\mathrm{CaCl}_{2}$ administration, resulting in complete azoospermia over a 12-month period whereas the effects of $\mathrm{CaCl}_{2}$ in lidocaine solution lasted for only six months. AbuAhmed (2015) has also reported absence of regeneration in germ cells and interstitial cells in another study with calcium chloride.

\section{Chlorhexidine}

Chlorhexidine, a sclerosing agent, produces azoospermia by causing tissue necrosis and sclerosis which further prevents passage of spermatozoa to vasa deferentia from epididymides (Pineda et al., 1977).

Barnett (1985) administered bilateral injection of $0.5 \mathrm{ml}$ of a $4.5 \%$ aqueous solution of chlorhexidinedigluconate into each tail of the epididymides of seven animals and reported azoospermic ejaculates in treated animals by day 35 after treatment. The author further reported that a large-scale application of this method was initiated in the Galapagos under the authority of the National Park Service.

\section{Glycerol}

Glycerol intratesticular injection in monkeys, hamsters, rabbits, and rats had resulted in a consistent elimination of spermatozoa in ejaculates with a minimal decrease in serum testosterone concentrations. Glycerol solution intratesticular injections to adult male dogs did not induce azoospermia in any dog and was found to be an ineffective method for sterilization of male dogs (Immegart and Threlfall, 2000). 


\section{Lactic acid}

The lactic acid intratesticular injection in immature dogs and mature dogs reduced testes size to a level of being undetectable in the scrotum by palpation at 7 weeks in immature dogs and produced degenerative changes and atrophy in the seminiferous tubules after 4 months of treatment in mature dogs as revealed in testicular tissue histopathological examination (Nishimura et al., 1992).

Methallibure, dexamethasone, metopiron and niridazole

Dixit (1979) administered intratesticular

injection of Methallibure, Dexamethasone, Metopiron and Niridazole in adult male dogs @ 100mg and histopathological examination of testicular tissues post 30 day of injection revealed spermatogenic arrest at the spermatid stage and empty lumen of epididymis and vas deferens without altering the general metabolic activities.

\section{Silver nitrate and formaldehyde}

Freeman and Coffey (1973) injected dog's vas deferens with $500 \mu \mathrm{l}$ of $10 \%$ silver nitrate and $3.6 \%$ formaldehyde and reported vas deferens lumen replacement by scar tissue and reduction in diameter of the vas over a distance of approximately $2 \mathrm{~cm}$ by both chemicals after 2 month of injection.

\section{Sodium chloride}

The hypertonic saline acts by creating local osmotic shock, massive infiltration of immune cells and degenerative changes in testicular seminiferous tubules (Kwak and Lee, 2013). Canpolat et al(2016) administered sodium chloride $20 \%$ solution intratesticularly till occurrence of tension in testes in adult and non-adult male dogs and reported testicular swelling in all dogs following injection and which reached at a peak within 48 hours. Histopathological examinations of testicular tissues at end of 60 days revealed focal coagulative necrosis with diffuse and severe degenerative changes in seminiferous tubules of non-adult dogs. The authors suggested that intra testicular injection of hypertonic saline could be an effective method for nonsurgical sterilization of the non-adult male dogs but not adult dogs in their conclusion.

\section{4-Vinylcyclohexene diepoxide}

Vinylcyclohexenediepoxide is a metabolite of 4-Vinylcyclohexene which is a chemical that is produced in the production of materials such as rubber, plastics and pesticides. Vinylcyclohexenediepoxide was given intraperitoneally for 8 days to adult male dogs @ 80 and $320 \mathrm{mg} / \mathrm{kg}$ and it caused down regulation of caspase- 8 and 9 at the level of apoptosis. The down regulation of caspase- 8 at the gene level shows that the chemical used damages the testicular tissue (Paksoy, 2018).

\section{Zinc formulations}

Zinc in higher concentrations inhibits the division, replication ofgerm cells and causes fragmentation of the cellularmembrane and nucleus (Bloomberg, 1996; Oliveira et al., 2007) and inhibits the binding of testosterone to the $5 \alpha$-reductase enzyme reducing serum concentrations of dihydrotestosterone (Oliveira et al., 2007).

Talsur, containing zinc tannate, developed by the National Institute of Immunology (NII) of India in 1988 was used in a street-dog control program in which $22 \%$ of treated dogs developed complications which lead to discontinuation of the formulation (Ansari et al., 2017).

Fahim et al., (1993) injected zinc arginine into the cauda epididymis of adult male dogs and reported that histopathological examination of 
testes after one year of injection revealed decrease in cross diameter of the rete testes and absence of sperm in epididymides of treated dogs. The authors concluded that one single intraepididymal injection of $50 \mathrm{mg}$ of zinc arginine causes sterility by blocking sperm transport from the testes to the epididymides without affecting spermatogenesis and testosterone production and offers a new, safe modality for permanent male chemical sterilization. Chaudhary et al(2018) administered zinc arginine solution@ $0.2 \mathrm{ml}$ into each cauda epididymis percutaneously into pre-pubertal dogs and surgically removed testis and epididymis from two animals for histopathological studies on day $10,20,30,40,50,60,70,80$ and 90 respectively and reported complete degeneration of epididymal tubules, fibrous tissue presence and loss of structural details in most of the tubules on day 20 and 30 after injection. The authors concluded that single intraepididymal injection of zinc arginine causes complete necrosis of the caudaepididymal tubules in pre- pubertal dogs and it can cause an irreversible loss of fertility in dogs.

Neutersol, an intratesticular injection that contains zinc gluconate neutralized to a $\mathrm{pH}$ of 7 by arginine, was the first drug approved by the Food and Drug Administration for use in the United States in 2003 for puppies 3 to 10 months of age with testicles measuring 10 to $27 \mathrm{~mm}$ in width (Memon, 2010). Since 2005 it has not been available in the United States after the patent holder and marketing company discontinued their relationship (Levy, 2006). However, the product has been brought back to certain markets renamed as Esterilsol $®$, sponsored by a company named Ark Sciences, Inc. (Ansari et al., 2017)

Oliveira et al (2007) administered zinc gluconate $\left(\right.$ Testoblock ${ }^{\circledR}$ ) to adult male dogs ranging from 8 months of age to 4 years intra testicularly. Transmission electron microscopy post 5 months of injection revealed degenerated Sertoli and Leydig cells, hyperplastic and hypertrophic smooth endoplasmic reticulum and numerous Golgi apparati in cytoplasm of elongated spermatids and lysis of acrosomal vesicles of round spermatids in Golgi phase. Histological examination of treated groups revealed seminiferous tubules in majority lined only by vacuolated Sertoli cells and authors suggested that change are irreversible and zinc-based solution Testoblock is effective as a chemical sterilant for dogs.

\section{Hormonal methods}

Canine contraception through hormonal manipulation was first reported by Murray and Eden in 1952 (Ansari et al., 2017). Several hormones such as androgens, antiestrogens, Gnrh agonists, Gnrh antagonists, progestins and prolactin have been used for control of fertility in male dogs.

\section{Androgens}

Testosterone has a suppressive effect on Gnrh release and spermatogenesis when administered at greater than physiological doses (Norman and Collop, 2014). Danazol, a synthetic derivative of 17a-ethinyl testosterone, administration to male dogs produced spermatogenic arrest at the spermatid stage and empty lumen of epididymis and vas deferens (Dixit, 1979).

Methyltestosterone administration orally to male dogs @ 50 mg/dog/day for 90 days decreased mean daily sperm output and mean testicular length but authors reported that change in daily sperm output and testicular length seemed to be temporary since similar decrease was not observed during recovery period (Freshman et al., 1990).

Mixed testosterone esters administration to male dogs @ $5 \mathrm{mg} / \mathrm{kg}$ produced a significant 
decline in semen quality, which occurred 3 weeks after treatment and persisted for 3 months and it was thought that the effect was probably related to suppression of gonadotrophin resulting in an effect on spermatogenesis (England, 1997).

\section{Antiestrogens}

Tamoxifen, a phenylethylene derivative belongs to the group of type I antioestrogens that competitively blocks estrogen receptors with a mixed antagonist-agonist effect. The degree of agonistic or antagonistic activity depends on the species, organ, tissue, or cell type that is being examined e.g. in the human tamoxifen exerts distinct antioestrogenic activities in the mammary gland while it exerts agonistic activities on the uterus (Hoffmann and Schuler, 2000).

Tamoxifen citrate @ $2.5 \mathrm{mg}$. was given orally for 28 days to male dogs which led to deterioration of semen quality to nadir values approximately one spermatic cycle after treatment and returned to pre-treatment values on the second cycle after treatment in all the dogs, except one young oligoazoospermic dog (Corrada et al., 2004).

\section{GnRH Agonists}

GnRH agonists suppress fertility by reversibly inhibiting the pituitary gonadal axis by downregulation of anterior pituitary $\mathrm{GnRH}$ receptors after the initial period of stimulation at sustained doses (Gobello, 2006).

Vickery et al(1984) administered once daily subcutaneous injections of nafarelin acetate @ $10 \mu \mathrm{g} / \mathrm{kg}$ for 42 days to adult male dogs and observed complete spermatogenesis suppression by day 38 of experiment and return of normal spermatogenesis following cessation of treatment in 128 days.

The GnRH agonist ethylamide was administered to prepubertal male by subcutaneous injection daily for 23 months @ $100 \mu \mathrm{g}$ and histopathological examination of testicular tissues revealed Sertoli cells, reserve spermatogonia, occasional primary spermatocye and absence of germ cells within somniferous tubules but normal seminal epithelium with all germ cells was observed after a recovery period of 14 months (Lacoste et al., 1989).

Leuprolide acetatesingle subcutaneous injection @ $1 \mathrm{mg} / \mathrm{kg}$ to adult male dogs resulted in decreased ejaculatory volume with disappearance of morphologically normal spermatozoa within $8 \mathrm{wk}$ which continued for 6 wk however twenty weeks after treatment with leuprolide acetate, a complete return to normal spermatogenesis was observed (Inaba et al., 1996).

Deslorelin was administered in dogs as a $6 \mathrm{mg}$ implant and reduced plasma concentrations of LH and testosterone to undetectable values within 20 days and 3 weeks respectively, had detrimental effects on semen quality within 56 weeks and no ejaculate were produced between 6 week and 48 week of treatment. The normal semen values were obtained by week 60 of treatment (Junaidi et al., 2003). It was approved for use in male dogs in New Zealand and Australia in 2003 and in the European Union (EU) in 2007 (Ansari et al., 2017).

\section{GnRH antagonists}

GnRH antagonists competitively block GnRH receptors sites in the anterior pituitary, exerting an immediate inhibitory effect on the gonadal axis (Heber et al., 1982). RS-68439 administartion in male dogs as a single injection @ $100 \mu \mathrm{g} / \mathrm{kg}$ keeps testosterone levels in the castrate range for more than $24 \mathrm{~h}$ and its repetitive daily injection results in dry ejaculates after 2 weeks (Vickery, 1985a). 
Acyline administartion in male dogs @ $330 \mu \mathrm{g} / \mathrm{kg}$ subcutaneously impaired second and third fractions of the ejaculate volume, sperm count and motility which improved slowly at the end of study (Valiente et al., 2007).

\section{Progestins}

Spermatogenesis can be disrupted by exogenous progestins because of suppression of gonadotropin secretion in males due to negative feedback mechanism (Kutzlerand Wood, 2006). The treatment of normal male dogs with a depot preparation of medroxyprogesterone acetate $(4 \mathrm{mg} / \mathrm{kg}$ ) reduced peripheral testosterone levels by $58 \%$ but no effects on testicular size and consistency, semen quality or libido were observed post 7 weeks of injection (Wright et al., 1979).

Megestrol acetate given orally for 7 days @ $2 \mathrm{mg} / \mathrm{kg}$ and $4 \mathrm{mg} / \mathrm{kg}$ produced no change in semen quality and minor secondary sperm abnormalities in treated dogs respectively in comparison with that of control dogs. Medroxyprogesterone acetate given subcutaneously @ 10 mg/ kg and 20 mg/ kg produced no change in semen quality and rapid and significant decrease in sperm motility, morphology and output respectively in comparison with that of control dogs (England, 1997).

\section{Prolactin}

Prolactin is essential in male dogs for growth and function of accessory sexual glands by augmenting the effects of androgens to these organs. Prolactin augments LH at the Leydig cells and enhances testosterone production in the testes. Prolactin hyperproduction inhibits testicular functions, sex hormone formation and spermatogenesis in humans affected with pituitary adenomas (Jöchle, 1997). Prolactin injection administration to dogs@600 @g/kg of body weight weekly for 6 months resulted in azoospermia in 3 months after treatment with decrease of sperm motility and increase of abnormal forms. Normal spermiogram was obtained after 5 months of treatment withdrawal (Shafik, 1994).

\section{Phytoestrogens}

Phytoestrogens are nonsteroidal, estrogen-like compounds which mimic reproductive hormone and are supposed to be defensive substances produced by plants which can modulate the fertility of herbivores. Over 300 plants of more than 16 different families contain substances with estrogenic activity (Farnsworth et al., 1975). There are three main classes of phytoestrogens: isoflavones, coumestans and lignans, which occur in either plants or their seeds (Murkies et al., 1998).

\section{Coumestrol}

Coumestrol can disrupt spermatogenesis and spermiogenesis by affecting the function and proliferation status of both germinal spermatogonia, intratubular and interstitial cells by binding with $\beta$ estrogen receptor in mammalian testis (Pérez-Riveroet al., 2009b).

Coumestrol feeding to adult male dogs @ $300 \mu \mathrm{g} / \mathrm{kg}$ on day $0,7,14,21$ and 28 of experiment caused oligospermic ejaculates with less than $20 \times 10^{6}$ spermatozoa as compared to the $352 \times 10^{6}$ spermatozoa from control animals. Histopathological examination revealed diminished spermatogonial layers and meiotic progress restricted to as much as having few round spermatids and no spermatozoa in seminiferous tubules (Pérez-Rivero et al., 2009b).

Pérez-Riveroet al(2009a) administered 300 $\mu \mathrm{g} / \mathrm{kg}$ coumestrol orally to male dogs, once a 
week for a 4 week period. Coumestrol feeding resulted in significantly decreased smelling frequency of male dogs for the container with vaginal secretions from estrus dog females and significantly decreased total number of ejaculated spermatozoids at the end of experiment and authors conclude that it induces alterations in the olfactory behavior along with an oligo and teratospermic effect.

Hispatopathological examination of testicular tissues at 12 hours, 24 hours, 7 day and 15th day post feeding of coumestrol @ $1.5 \mathrm{mg} / \mathrm{kg}$ to adult male dogs revealed unidentifiable stages of seminiferous epithelial cycle and spermiogenesis in the treated dogs without any histopathological lesions on the structure of spermatogonial and sertoli cells (Kumar, 2017a).

Another study by same authors with same experimental design observed normal efferent ductules epithelium after coumestrol feeding (Kumar, 2017b) and authors concluded that oral feeding of coumestrol @ $1.5 \mathrm{mg} / \mathrm{kg}$ cannot be used for sterilization of male dogs. Similarly coumestrol oral administration to adult male dogs @ 300 and $500 \mu \mathrm{g}$ on days 0 , $7,14,21$ and 28 resulted in absence of any adverse effects on efferent ductules cellular architecture (Kumar, 2016).

\section{Immunological methods}

The theory behind immunocontraception/ immunosterilization is the induction of the production of antibodies against specific targets such as testicular proteins, spermatozoa, Gnrh, LH receptors and zonapellucida proteins which consequently affects fertility temporary and permanently respectively, however, at present, there are no contraceptive vaccines available which have been licensed for contraception or sterilization of male dogs (Munks, 2012; Maenhoudt et al., 2014).

\section{BCG}

BCG acts by producing the local inflammatory response which is induced by the bacilli that enables the lymphoid cells to gain access to the testicular apparatus and elicit an immunological reaction against the proteins whose ontogenesis takes place with the onset of spermatogenesis and to which the body is not tolerant. A single intratesticular injection of 10 - 110 units of BCG suspended in saline in each testis rendered the dog's azoospermic within 3-6 weeks. Azoospermia was maintained up to 50-325 days of the observation period (Naz and Talwar, 1981).

\section{Complete and incomplete Freund's adjuvant Freund's}

Complete Freund's Adjuvant intratesticular injection caused azoospermia in adult male dogs and histologically it caused severe granulomatous reaction with widespread degeneration and vacuolation of the tubules. It did not cause damage to the tubules and animals on maturation had normal testicular histology with active spermatogenesis and donated good quality semen when injected into juvenile animals. Administration of the incomplete Freund's adjuvant caused oligospermia but not azoospermia and the sperm count increased in the semen of these dogs after 6 weeks (Naz and Talwar, 1981).

\section{GnRH immunization}

GnRH is coupled with carrier materials because of its too small size as an antigen in order to induce production of neutralizing antibody against it. Therefore, GnRH has been conjugated with T-helper epitopes, tetanus toxoid and rotavirus VP6 protein.

GnRH fusion protein conjugated with CDV Th cell epitope p35 induced high levels of $\mathrm{GnRH}$-specific antibodies in the vaccinated 
male dogs and caused a regression of testicular functions in the dogs (Jung, et al., 2005).

The vaccination of male dogs with $\mathrm{N}$-terminal modified GnRH conjugated to tetanus toxoid did not display any significant arrest in testicular spermatogenesis with only a 5\% decrease in activity compared to untreated animals (Ferro et al., 2004).

The subcutaneous injection of a commercial canine GnRH vaccine (Canine Gonadotropin Releasing Factor Immunotherapeutic; Pfizer Animal Health, Exton, PA, USA) labelledfor management of benign prostatic hyperplasia in intact male dogs produced an elevated $\mathrm{GnRH}$ antibody titer, decreased $\mathrm{LH}$ and testosterone concentrations and decreased testicular volume, which reversed by the end of the study period of 20 weeks (Donovan et al., 2012).

\section{LHRH immunization}

Male dogs were immunized against LHRH conjugated to tetanus toxoid which led to development of antibodies against LHRH by week 5 and by week 10 serum testosterone levels were comparable to those in castrated dogs Antibodies against LHRH declined and serum testosterone remained at castration levels in following 28 weeks and serum testosterone levels were restored to the normal range after additional three month rest (Ladd et al., 1994).

Immunization of dogs with bovine luteinizing hormone impaired dog's ability to ejaculate by 2 to 5 wk after the first immunizing dose without visibly affecting libido and penile erection. The effects of immunization were apparent by high levels of antibodies and reproductive dysfunction for as long as $52 \mathrm{wk}$ in three of four dogs in the long-term study (Lunnen et al., 1974).

\section{Miscellaneous compounds}

\section{$\alpha$-chlorohydrin}

$\alpha$-chlorohydrin is an alkylating agent that causes of depletion of spermatogenic elements from the seminiferous tubules. Spermatogenesis was inhibited within 33 days in dogs after single high dose $(70 \mathrm{mg} / \mathrm{kg})$ or chronic administration ( $8 \mathrm{mg} / \mathrm{kg}$ for 30 days) of $\alpha$-chlorohydrin. These effects were reversible within 100 days following treatment (Dixit et al., 1975; Kutzler and Wood, 2006).

\section{Clove oil}

The main active component of clove oil is Eugenol which is said to possess various biological properties like antiviral, antioxidant and anti-inflammatory. Eugenol at low concentrations usually acts as an antioxidant and anti-inflammatory agent, whereas at higher concentration act as a pro-oxidant causing increased generation of tissuedamaging free radicals (Jaganathan and Supriyanto, 2012).

Abu-Ahmed (2015) administered single bilateral intra-testicular injection of clove oil in dogs and microscopic examination of testes at 60 days after injection revealed atrophy and degeneration of the seminiferous tubules with loss of their normal architectures. Moreover, there were disintegration and washing out of most of their germ cell, irregular and disrupted basal lamina with few necrotic cells desquamated within the tubular lumen. The authors concluded that single bilateral intratesticular injection of clove oil can cause chemical sterilization of dogs and it has an advantage over calcium chloride as it didn't induce pain and irritation to the dogs.

\section{Embelin}

Embelin is the major active constituent in the fruits commonly known as vidanga which was 
first chemically investigated by Scott in 1888 (Poojari, 2014). Embelin, at an oral dose of 80 $\mathrm{mg} / \mathrm{kg}$ every alternate day for 100 days caused significant reduction in the weight of testes and epididymis, the diameter of the seminiferous tubule and Leydig cells and biochemical changes in testes and epididymis of male dogs. Histologically, it showed varying degrees of spermatological alterations which were recouped after a 250-day recovery period (Dixit and Bhargava, 1983).

\section{Ketoconazole}

Ketoconazole is an inhibitor of cellular division and has been shown to exert spermatostatic effects in several species including the dog, rabbit, monkey and man (Kutzler and Wood, 2006).Its oral administration to adult male dogs @ 50-246 $\mathrm{mg} / \mathrm{kg}$ was associated with a decline in motility of sperm in ejaculates within 4 hours of dosing (Vickery et al., 1985b). However, Heckman et al(1992) in their study with mice and rats observed lack of correlation between steroid levels and sperm immobilization, along with rapid in vivo and in vitro effects on sperm motility and they concluded that ketoconazole is probably not a viable approach to the development of a male contraceptive.

In conclusion, the development of an ideal chemical sterilizing agent seems equivalent to Holy Grail search but till then other suitable/available chemical methods which have been tried can be used to curb stray dog population and various stakeholders should put more efforts for the development of a wonder chemical sterilizing drug.

\section{References}

Abu-Ahmed, H.M. 2015. Chemical Sterilization of Dogs using Single Bilateral Intra-testicular Injection of
Calcium Chloride or Clove Oil. Alexandria Journal of Veterinary Sciences. 45: 26-32.

ACC\&D. 2013. Contraception and Fertility Control in Dogs and Cats. A Report of the Alliance for Contraception in Cats \& Dogs.

Ansari, A.S., Badar, A. and Lohiya, N.K. 2017. Fertility Control Modalites in Animals: An Overview. BAOJ. Vet. Sci. 1: 004.

Barnett, B.D. 1985. Chemical vasectomy of domestic dogs in the Galapagos islands. Theriogenology.23(3): 499509.

Bekheet, S.H.M. 2010. Cadmium chloride rapidly alters both BTB tight junction proteins and germ cells in young rat testes. Egypt. Acad. J. Biolog. Sci. 2 (1): 59-74.

Bloomberg, M.S. 1996. Surgical neutering and non-surgical alternatives. J. Am. Vet. Med. Assoc. 208: 517-519.

Butcher, R.L. and Keuster, T.D. 2013. DogAssociated Problems Affecting Public Health and Community Well-Being. In: Dogs, zoonoses and public health. (Eds.) Macpherson, C.N.L., Meslin, F.X. and Wandeler, A.I. CABI. Pp. 24-37.

Canpolat, I., Karabulut, E. and Eroksuz, Y. 2016. Chemical Castration of Adult and non-Adult Male Dogs with Sodium Chloride Solution. IOSR Journal of Agriculture and Veterinary Science. 9(12/1): 09-11.

Chaudhary, R., Sharma, A.K., Mehra, U.S., Dutt, R., Kumar, P. and Yadav, R. 2018. Histopathological Studies on Intra Epididymal Zinc Arginine Administration in Pre-Pubertal Dogs. Int. J. Curr. Microbiol. App. Sci. 7(5): 569-581.

Corrada, Y., Arias, D., Rodri'guez, R., Spaini, E., Fava, F. and Gobello, C. 2004. Effect of tamoxifen citrate on 
reproductive parameters of male dogs. Theriogenology. 61: 1327-1341.

Dixit, S.K. and Bhargava, S.K. 1983. Reversible contraception-like activity of embelin in male dogs (Canisindicus Linn). Andrologia. 15: 486.

Dixit, V.P. 1979. Chemical sterilization of male dogs (Canis familiaris) after single intratesticular administration of methallibure (ICI-33828), dexamethasone, metopiron (SU-4885, Ciba), niridazole (33644-Ba, Ciba), alpha-chlorohydrin

(U-5897) \&danazol. Indian J. Exp. Biol. 17(9): 937-40.

Dixit, V.P., Lohiya, N.K., Arya, M. and Agrawal, M. 1975. Reversible changes in the testes and epididymides of dog treated with alpha-chlorohydrin. Acta. Biol. Med. Ger. 34:1851-1856.

Donovan, C.E., Greer, M. and Kutzler, M.A. 2012. Physiologic responses following gonadotropin-releasing hormone immunization in intact male dogs. Reprod. Domest. Anim. 47(6): 403 405.

England, G.C. 1997. Effect of progestogens and androgens upon spermatogenesis and steroidogenesis in dogs. J. Reprod. Fertil. Suppl.51: 123-138.

Fahim, M.S., Wang, M., Sutcu, M.F., Fahim, Z. and Yougquist, R.S. 1993. Sterilization of dogs with intraepididymal injection of zinc arginine. Contraception. 47: 107-122.

Farnsworth, N.R., Bingel, A.S., Cordell, G.A., Crane, F.A. and Fong, H.H.S. 1975. Potential value of plants as sources of new antifertility agents II. J. Pharm. Sci. 64: 717-754.

Ferro, V.A., Khan, M.A.H., McAdam, D., Colston, A., Aughey, E., Mullen, AB., Waterston, M.M. and Harvey, M.J.A. 2004. Efficacy of an anti-fertility vaccine based on mammalian gonadotrophin releasing hormone
(GnRH-I)-a histological comparison in male animals. Veterinary Immunology and Immunopathology. 101: 73-86.

Freeman, C. and Coffey, D.S. 1973. Sterility in male animals induced by injection of chemical agents into the vas deferens. FertilSteril. 24(11): 884-890.

Freshman, J.L., Olson, P.N., Amann, R.P., Carlson, E.D., Twedt, D.C. and Bowen, R.A. 1990. The effects of methyltestosterone on reproductive function in male greyhounds. Theriogenology. 33: 1057-1073.

Gobello, C. 2006. Dopamine agonists, antiprogestins, anti-androgens, long-termrelease GnRH agonists and antiestrogens in canine reproduction: a review. Theriogenology. 66(6-7): 1560-1567.

Gompper, M.E. 2014. The dog-humanwildlife interface: assessing the scope of the problem. In: Free-Ranging Dogs \& Wildlife Conservation. (Ed.) Gompper, M.E. Oxford University Press, Oxford, Pp.25.

Hassan, A. and Fromsa, A. Review on chemical sterilization of male dogs. Int. J. Adv. Res. 5(11): 758-770.

Heber, D., Dobson, R., Swerdloff, R.S., Channabasavaiah, K. and Stewart, J.M. 1982. Pituitary receptor site blockade by a gonadotropin-releasing antagonist in vivo: mechanism of action. Science. 216: 420-1.

Heckman, W.R., Kane, B.R., Pakyz, R.E. and Cosentino, M.J. 1992. The effect of ketoconazole on endocrine and reproductive parameters in male mice and rats. J. Androl. 13(3): 191-198.

Hoffmann, B. and Schuler, G. 2000. Receptors blockers-general aspects with respect to their use in domestic animal reproduction. Anim. Reprod. Sci. 60-61: 295-312.

Immegart, H.M. and Threlfall, W.R. 2000. Evaluation of intratesticular injection 
of glycerol for nonsurgical sterilization of dogs. Am. J. Vet. Res. 61(5): 544-549.

Inaba, T., Umehara, T., Mori, J., Torii, R., Tamada, H. and Sawada, T. 1996. Reversible suppression of pituitarytesticular function by a sustainedrelease formulation of a $\mathrm{GnRH}$ agonist (leuprolide acetate) in dogs. Theriogenology. 46(4): 671-677.

Jaganathan, S.K. and Supriyanto, E. 2012. Antiproliferative and molecular mechanism of eugenol-induced apoptosis in cancer cells. Molecules. 17: 6290-6304.

Jana, K. and Samanta, P.K. 2007. Sterilization of male stray dogs with a single intratesticular injection of calcium chloride: a dose-dependent study. Contraception. 75(2007): 390-400.

Jöchle, W. 1997. Prolactin in Canine and Feline Reproduction. Reprod. Dom. Anim. 32: 183-193.

Junaidi, A., Williamson, P.E., Cummins, J.M., Martin, G.B., Blackberry, M.A. and Trigg, T.E. 2003. Use of a new drug delivery formulation of the gonadotrophin-releasing hormone analogue Deslorelin for reversible long-term contraception in male dogs. Reprod. Fertil. Dev. 15: 317-322.

Jung, M.J., Moon, Y.C., Cho, I.H., Yeh, J.Y., Kim, S.E., Chang, W.S., Park, S.Y., Song, C.S., Kim, H.Y., Park, K.K., McOrist, S., Choi, I.S. and Lee, J.B. 2005. Induction of castration by immunization of male dogs with recombinant gonadotropin-releasing hormone (GnRH)-canine distemper virus (CDV) $\mathrm{T}$ helper cell epitope $\mathrm{p} 35$. J. Vet. Sci. 6(1): 21-24.

Kumar, R., Sharma, A.K. and Pandey, A. K. 2016. Effect of Coumestrol on Efferent Ductules in Dogs. Journal of Animal Research: 6(3): 499-501.

Kumar, R., Sharma, A.K. and Pandey, A. K. 2017a. Effect of Coumestrol Feeding on Sterilization of Male Dog. Int. J. Pure App. Biosci. 5(5): 178-182.

Kumar, R., Sharma, A.K. and Pandey, A. K. 2017b. Effects of Oral Feeding of Coumestrol on Efferent Ductules in Dogs Journal of Animal Research. 7(4): 793-795.

Kumar, S. 2002. Stray dogs are a growing threat to public health. B. M. J. 325(7355): 66.

Kutzler, M. and Wood, A. 2006. Non-surgical methods of contraception and sterilization. Theriogenology. 66(3): 514-525.

Kwak, B.K. and Lee, S.H. 2013. Intratesticular Injection of Hypertonic Saline: Non-Invasive Alternative Method for Animal Castration Model. Dev. Reprod. 17(4): 435-440.

Lacoste, D., Dubé, D., Trudel, C., Bélanger, A. and Labrie, F. 1989. Normal gonadal functions and fertility after 23 months of treatment of prepubertal male and female dogs with the GnRh agonist [D-Trp6, des-GlyNH2(10)]GnRHethylamide. J. Androl. (6): 456-465.

Ladd, A., Tsong,Y. Y., Walfield,A.M. and Thau,R.1994. Development of an Antifertility Vaccine for Pets Based on Active Immunization against Luteinizing Hormone-Releasing Hormone. Biology of Reproduction. 51: 1076-1083.

Leavesley, J.H. 1980. Brief history of vasectomy. Fam. Plann. Inf. Serv. 1980 1(5): 2-3.

Leoci, R., Aiudi, G., Silvestre, F., Lissner, E.A. and Lacalandra, G.M. 2014. Alcohol diluent provides the optimal formulation for calcium chloride nonsurgical sterilization in dogs. Acta Veterinaria Scandinavica. 56: 62.

Levy, J.K. 2006. Neutersol: What worked? What didn't? What's next? (abstr), in 
Proceedings. 3rd IntSymp Nonsurgical Contraceptive Methods Pet Population Control.

Lunnen, J.E, Faulkner, L.C., Hopwood, M.L. and Pickett, B.W.1974. Immunization of dogs with bovine luteinizing hormone. Biol. Reprod. 10(4): 453 460.

Maenhoudt, C., Santos, N.R. and Fontbonne, A. 2014. Suppression of Fertility in Adult Dogs. Reprod. Dom. Anim. 49 (2): 58-63

Memon, M.A. 2010. Nonsurgical methods of contraception in dogs and cats: Where are we now? Veterinary Medicine. Retrieved from: http://veterinary medicine.dvm360.com/nonsurgicalmethods-contraception-dogs-and-catswhere-are-we-now. Accessed on June 6, 2018.

Munks, M.W. 2012. Progress in development of immunocontraceptive vaccines for permanentnon-surgical sterilization of cats and dogs.Reprod. Domest. Anim. 47(4): 223-227.

Murkies, A.L., Wilcox, G. and Davis, S.R. 1998. Clinical review 92: Phytoestrogens. J. Clin. Endocrinol. Metab. 83(2): 297-303.

Murty, T. A. and Sastry, G. A. 1978. The effects of cadmium chloride injection on the histopathology of the testis and the prostate in dog. I. Intratesticular procedure. Indian Vet. J. 55(1): 368371.

Naz, R.K. and Talwar, G.P. 1981. Immunological sterilization of male dogs by BCG. Int. J. Androl. 4(1): 111-128.

Nishimura, N., Kawate, N., Sawada, T. and Mori, J. 1992. Chemical Castration by a Single Intratesticular Injection of Lactic Acid in Rats and Dogs. Journal of Reproduction and Development. 38(4): 263-266.

Norman, S.T. and Collop, T.C. 2014. Male
Animal Contraception. In: Animal Andrology: Theories and Applications. (Eds.) Chenoweth, P.J. and Lorton, S.P. CABI. Pp. 488.

OIE. 2011. Terrestrial Animal Health Code.

Retrieved from: https://www.oie.int/doc/ged/D10905.P DF. Accessed on June 12, 2018.

Oliveira, E.C., Moura, M.R., Silva, V.A. Jr., Peixoto, C.A., Saraiva, K.L., de Sá MJ, Douglas, R.H. and de Pinho Marques, A. Jr. 2007. Intratesticular injection of a zinc-based solution as a contraceptive for dogs. Theriogenology. 68(2): 137-45.

Paksoy, Z. 2018. The effects of 4vinylcyclohexene diepoxide on gene expression in dog testes. Inter. J. Vet. Sci. 7(2): 60-64.

Pérez-Rivero, J.J., Martinez-Maya, J.J., Perez-Martinez, M., Aguilar-Setien, A. and Serrano, H. 2009a. Effect of coumestrol on sperm production and smell exploratory behavior in dogs stimulated with vaginal mucus. Vet. Mex. 40(1): 9-16.

Pérez-Rivero, J.J., Martinez-Maya, J.J., Perez-Martinez, M., Aguilar-Setien, A., Garcia-Suarez, M.D. and Serrano, H. 2009b. Phytoestrogen treatment induces testis alterations in dogs. Potential use in population control. Vet. Res. Commun. 33: 87-95.

Pineda, M.H., Reimers, T.J., Faulkner, L.C., Hopwood, M.L. and Seidel, G.E. 1977. Azoospermia in dogs induced by injection of sclerosing agents into the caudae of the epididymides. American J. Veterinary Research. 38: 831-838.

Poojari, R. 2014. Embelin - a drug of antiquity: shifting the paradigm towards modern medicine, Expert Opinion on Investigational Drugs. 23(3): 427-444.

Shafik, A. 1994. Prolactin injection, a new 
contraceptive method: experimental study. Contraception. 50: 191-9.

Supreme Court of India, 2016. Animal Welfare Board of India Versus People for Elimination of Stray Troubles \&Ors Respondent (S) Dated 04/10/2016. Retrieved from: https://supremecourtofindia.nic.in/pdf/ cir/2016-10-04_1475587175.pdf

Accessed on June 1, 2018.

Talwar,G.P., Naz,R.K., Das,C. and Das, R.P. 1979. A practicable immunological approach to block spermatogenesis without loss of androgens. Proc. Natl. Acad. Sci. USA. 76(11): 5882-5885.

Valiente, C., Y. Corrada, P.E., de la Sota; Gerez, P. G. and Gobello, C. 2007. Effect of the GnRH antagonist, acyline, on canine testicular characteristics. Theriogenology. 68: 687-692.

Vickery, B. H. 1985a. Comparisons of the Potential Utility of LHRH Agonists and Antagonists for Fertility Control. Journal of Steroid Biochemistry. 23(5/2): 779-791.

Vickery, B.H., Burns, J., Zaneveld, L.J., Goodpasture, J.C. and Bergström, K. 1985b. Orally administered ketoconazole rapidly appears in seminal plasma and suppresses sperm motility. Adv. Contracept. 1(4): 34153.

Vickery, B.H., McRae, G.I., Briones, W., Worden, A., Seidenberg, R., Schanbacher, B.D. and Falvo, R. 1984. Effects of an LHRH agonist analog upon sexual function in male dogs. Suppression, reversibility, and effect of testosterone replacement. J. Androl. 5(1): 28-42.

Wright, P.J., Stelmasiak, T., Black, D. and Sykes, D. 1979. Medroxyprogesterone acetate and reproductive processes in male dogs. Aust. Vet. J. 55:437-438.

WSPA, 2007. Retrieved from: http://www.icamcoalition.org/downloads/Nonsurgical\%20methods $\% 20$ for $\% 20$ contr olling\%20the \%20reproduction $\% 20$ of $\% 20$ dogs $\% 20$ and $\% 20$ cats.pdf. Accessed on June 5, 2018.

www.insightsonindia.com. 2016. Retrieved from:

http://www.insightsonindia.com/wpcontent/uploads/2016/11/Issue-ofStray-Dogs-in-India.pdf. Accessed on June 1, 2018.

www.michelsonprizeandgrants.org. Retrieved from https://www.michelsonprize andgrants.org/michelson-prize/ Accessed on June 12, 2018.

\section{How to cite this article:}

Rakesh Kumar, Nitin Soni, Sandeep Kumar and Anand Kumar Pandey. 2018. Chemical Control of Fertility in Male Dogs: A Review. Int.J.Curr.Microbiol.App.Sci. 7(07): 1760-1773. doi: https://doi.org/10.20546/ijcmas.2018.707.209 